\title{
The Microstructure and Mechanical Properties of EP741NP Powder Metallurgy Disc Material
}

\author{
John Radavich ${ }^{1}$, David Furrer ${ }^{2}$, Tadeu Carneiro ${ }^{3}$, Joseph Lemsky ${ }^{4}$ \\ ${ }^{1}$ Micro-Met Laboratories, 209 North Street, W. Lafayette, IN 47906, USA \\ ${ }^{2}$ Rolls-Royce, PO Box 420, Speed Code S-48, Indianapolis, IN 46206-0420 USA \\ ${ }^{3}$ Reference Metals Company, 1000 Old Pond Road, Bridgeville, PA 15017, USA \\ ${ }^{4}$ Ladish Forging, PO Box 8902, Cudahy, WI 53110, USA
}

Keywords: P/M, powder metallurgy, heat treatment, microstructure, stress rupture, EP741NP

\begin{abstract}
An effort to study the heat treatment methods and resultant mechanical properties of Russian powder metallurgy (P/M) alloy EP741NP has been undertaken. This effort has involved the detailed assessment of microstructures and mechanical properties from a sample of a production turbine engine disc as well as the manufacture, processing and characterization of two developmental lots of P/M EP741NP material processed by atomization, extrusion, isothermal forging and heat treating. The effects of processing and composition on the structure and properties of powder metallurgy superalloys have been studied as part of an on-going effort to compare and contrast the physical metallurgy and mechanical property capabilities of EP741NP and similar alloys, such as AF115, AF21DA6, Alloy-10 and LSHR. From detailed characterization of developmental EP741NP heats, it has been determined that the published Russian heat treatment for EP741NP was not the thermal cycle used to produce the EP741NP material extracted from a production disc. The identified heat treatment route was subsequently utilized to process additional developmental material. The microstructure and mechanical properties from resultant material matched well with the previously evaluated production material. The thermal process for this alloy is aimed at very high temperature applications where notched stress-rupture and long-life stability are critical.
\end{abstract}

\section{Introduction}

As turbine engine temperatures and stresses increase, more interest is focused on achieving greater material properties and achieving control of grain size by use of powder metallurgy (P/M) technology. Previous studies on advanced $\mathrm{P} / \mathrm{M}$ superalloys have shown that alloy composition and processing route greatly influence the final microstructure and mechanical properties that can be achieved. [1, 2, 3] Recent efforts to study the Russian $\mathrm{P} / \mathrm{M}$ superalloy EP741NP have shown that phase selection and final microstructure can be greatly affected by processing route [4, $5,6,7]$.
In these previous investigations, it was shown that as-hot isostatically pressed (HIP) and thermally processed materials can produce extensive prior particle boundaries (PPBs). Deformation processing was shown to eliminate these detrimental features. Heat treatment of wrought processed EP741NP by various routes showed significant changes in microstructure and mechanical property response. Rapid cooling from supersolvus temperatures and single, low temperature aging produced the greatest strength and creep capability. The effect of hafnium (Hf) content variation on these properties was not evident, but it was thought that hafnium may have an impact on notch ductility, which led to notched stress-rupture testing in the current effort.

Alloy design and optimization efforts are continuing to address the ever changing and further demanding needs for turbine engine applications. Table 1 lists the chemistries for a range of advanced $\mathrm{P} / \mathrm{M}$ superalloys along with the alloys investigated within this program.

Developing the optimum microstructure for the maximum mechanical property capabilities has been the focus of many alloy development and application assessment efforts. There is an increasing need for higher temperature capable disc materials. Efforts to improve notch-sensitivity by incorporation of hafnium have also been previously reported [8].

This current effort is focused on three main areas: 1) Validation of the heat treatment process utilized for the production EP741NP disc material previously characterized; 2) Evaluation of the microstructure evolution of EP741NP and the effects of microstructure on mechanical properties capabilities for potentially very high temperature applications; and 3) Further understanding of the potential beneficial effects of hafnium and niobium on microstructure evolution and high temperature mechanical properties.

TABLE 1. The chemistry of several advanced P/M superalloys along with the chemistry of EP741NP and program alloys (Alloy-1 and Alloy-2). (weight \%)

$\begin{array}{lllllllllllll}\text { ALLOY } & \mathrm{Al} & \mathrm{Co} & \mathrm{Cr} & \mathrm{Hf} & \mathrm{Mo} & \mathrm{Nb} & \mathrm{Ti} & \mathrm{W} & \mathrm{Zr} & \mathrm{B} & \mathrm{C} & \mathrm{Ta} \\ \text { EP741NP } & 5.1 & 15.8 & 9.0 & 0.25 & 3.9 & 2.6 & 1.8 & 5.5 & <0.015 & <0.015 & 0.04 & -- \\ \text { Alloy-1 } & 5.17 & 15.76 & 7.98 & 0.26 & 3.71 & 2.54 & 1.82 & 5.49 & 0.041 & 0.0094 & 0.041 & -- \\ \text { Alloy-2 } & 5.02 & 15.63 & 8.13 & -- & 3.61 & 2.62 & 1.82 & 5.50 & 0.015 & 0.0088 & 0.053 & -- \\ \text { AF115 } & 3.8 & 15 & 10.7 & 0.75 & 2.8 & 1.7 & 3.9 & 5.9 & 0.05 & 0.02 & 0.05 & -- \\ \text { AF2-1DA6 } & 4.6 & 10.0 & 12.0 & -- & 2.75 & -- & 2.8 & 6.5 & 0.1 & 0.015 & 0.04 & 1.5 \\ \text { Alloy-10 } & 3.8 & 15.0 & 11.0 & -- & 2.5 & 1.8 & 3.8 & 5.7 & 0.10 & 0.03 & 0.04 & -- \\ \text { LSHR } & 3.5 & 21.0 & 13.0 & -- & 2.7 & 1.5 & 3.5 & 4.3 & 0.05 & 0.03 & 0.03 & 1.6\end{array}$




\section{Experimental Procedure and Results}

A sample of a Russian turbine disc made from EP741NP was evaluated for microstructure and mechanical properties. Two heats of $\mathrm{P} / \mathrm{M}$ material were produced and processed into forgings with the EP741NP chemistry with and without hafnium. The manufacture of two P/M EP741NP-type materials was performed by atomization, extrusion, isothermal forging and heat treatment. The details of the manufacturing route have been presented previously [6].

Heat Treatment Development. The sample of Russian disc material was evaluated in the as received production heat treated condition. The published heat treatment for EP741NP is as follows: $1210^{\circ} \mathrm{C} / 8 \mathrm{hrs} /$ Furnace Cool (FC) to $1160^{\circ} \mathrm{C} /$ Air Cool (AC) $+871^{\circ} \mathrm{C} / 32 \mathrm{hrs} / \mathrm{AC}$. [4]. Isothermally forged pancakes were produced from Alloy-1 and Alloy-2. One half of each forging was heat treated per the published production heat treatment route. One half of each forging was heat treated with a route similar to other western alloys: $1210^{\circ} \mathrm{C} / 1 \mathrm{hr} / \mathrm{AC}+760^{\circ} \mathrm{C} / 16 \mathrm{hrs} / \mathrm{AC}$.
Additional heat treatments were subsequently performed on each alloy to further investigate the possible heat treatment route used for the production disc material. This effort allowed assessment of the heat treatment affect on phase and mechanical property evolution in Alloy-1 and Alloy-2 in comparison to the as-received disc material. The identified heat treatments involved solution heat treating at $1210^{\circ} \mathrm{C} / 2 \mathrm{hrs}$ followed by controlled furnace cooling to between $871^{\circ} \mathrm{C}$ and $760^{\circ} \mathrm{C}$ and air cooling to room temperature; and aging at $871^{\circ} \mathrm{C} / 32 \mathrm{hrs}$ and air cooling to room temperature. Additionally, a second, subsolvus solution heat treatment was also studied. The effect of cooling rate for the furnace cooling step was also investigated. Extensive metallography was performed on these samples, including selective etching and scanning electron microscopy (SEM) characterization, and phase extraction and X-ray diffraction assessment. Tensile, creep and stress-rupture testing was also performed. The heat treatments investigated within this program are graphically shown in Figure 1.

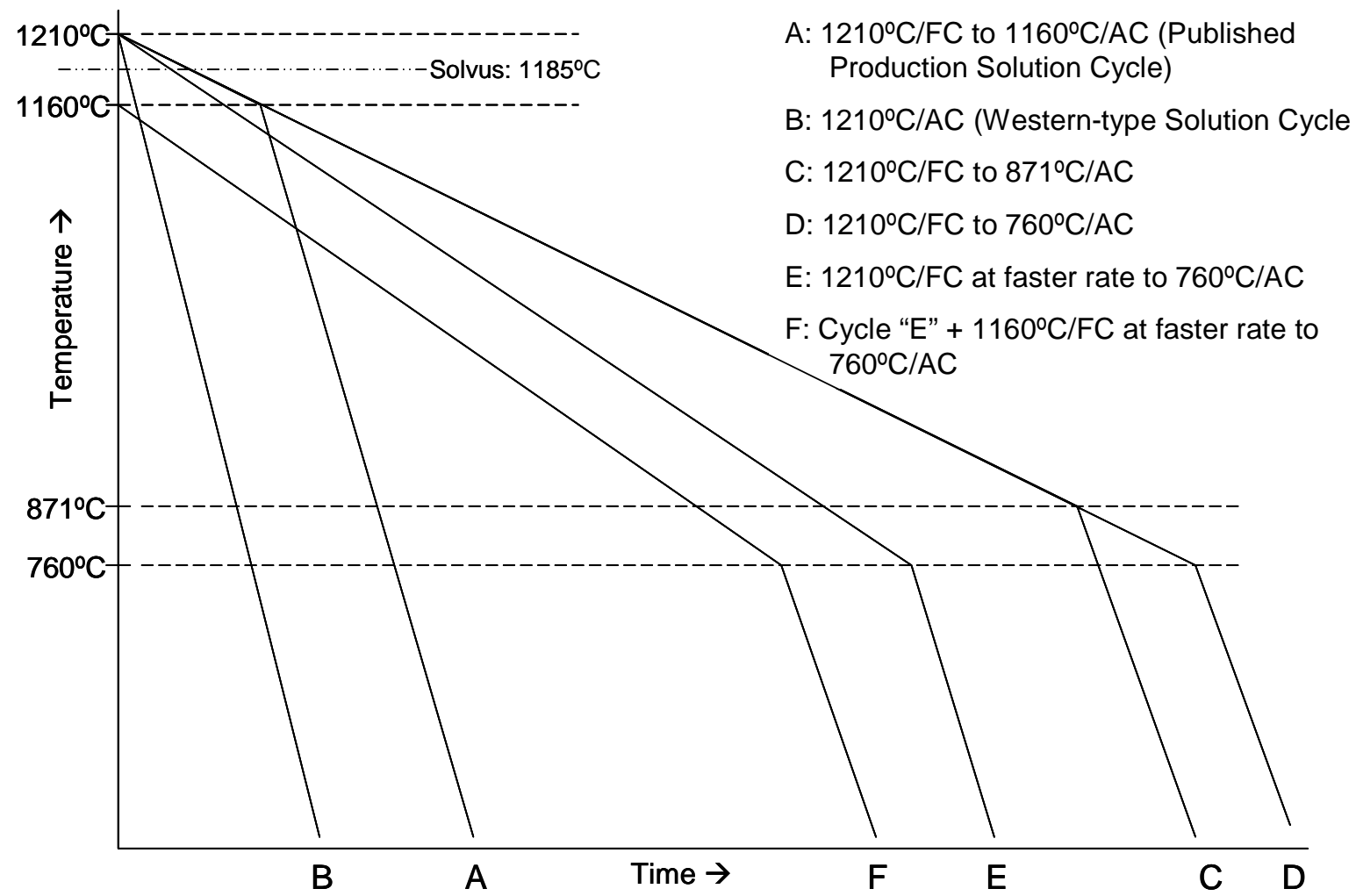

Figure 1. Schematic of the solution heat treatment cycles assessed in the characterization of EP741NP program material.

\section{Results}

Microstructure Evolution and Phase Selection. The microstructure of the Russian disc material was comprised of a high density of very cuboidal gamma-prime as seen in Figure 2.
The microstructure evolution of EP741NP material was evaluated through a series of laboratory heat treatment trials. The resultant microstructures from Alloy-1 and Alloy-2 were very similar. The primary differences were the formation of $\mathrm{Mu}$ phase and a slightly reduced gamma-prime size within the hafnium bearing samples. 
Further details of these comparisons have been previously reported [7].

Microstructures and phases in the EP741NP alloys heat treated to the published and western-type heat treatment methods were assessed in the as-heat treated condition and have been reported previously [6]. Figures 3 and 4 show representative microstructures that resulted from these thermal cycles.

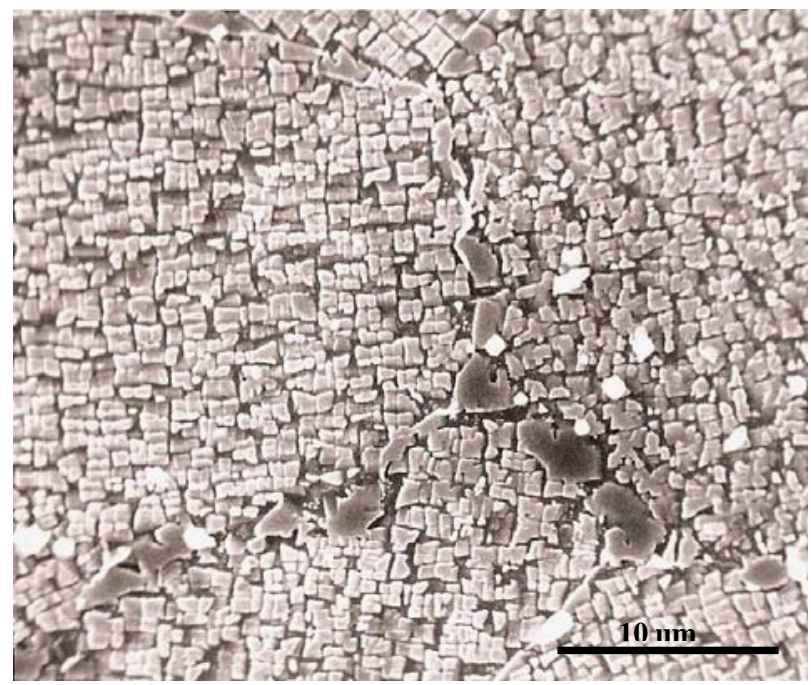

Figure 2. Photomicrograph of the microstructure of EP741NP from a fully processed Russian turbine engine disc. [1]

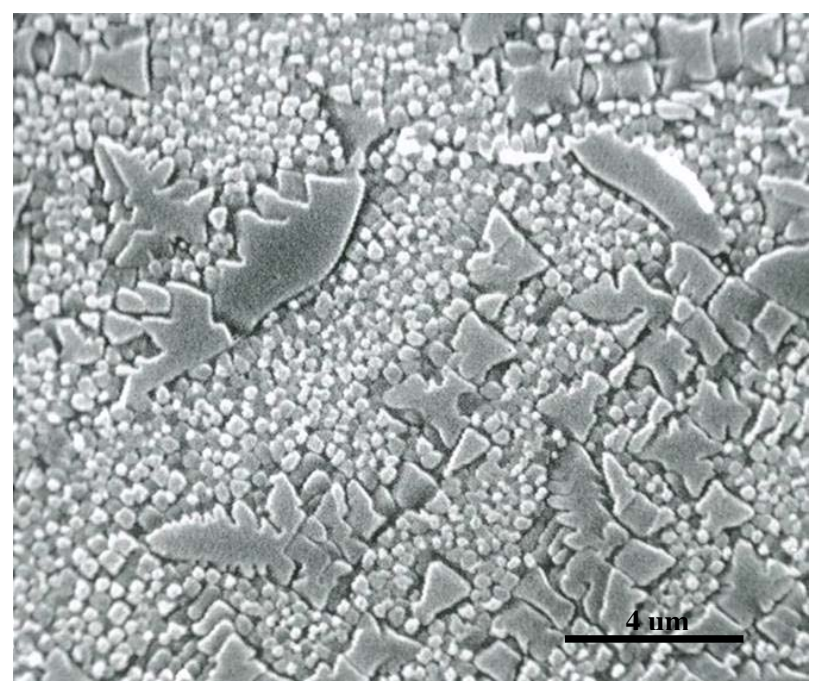

Figure 3. Photomicrograph of the microstructure of Alloy-1 after processing with the published heat treatment for EP741NP. (Solution heat treatment cycle A + age.)

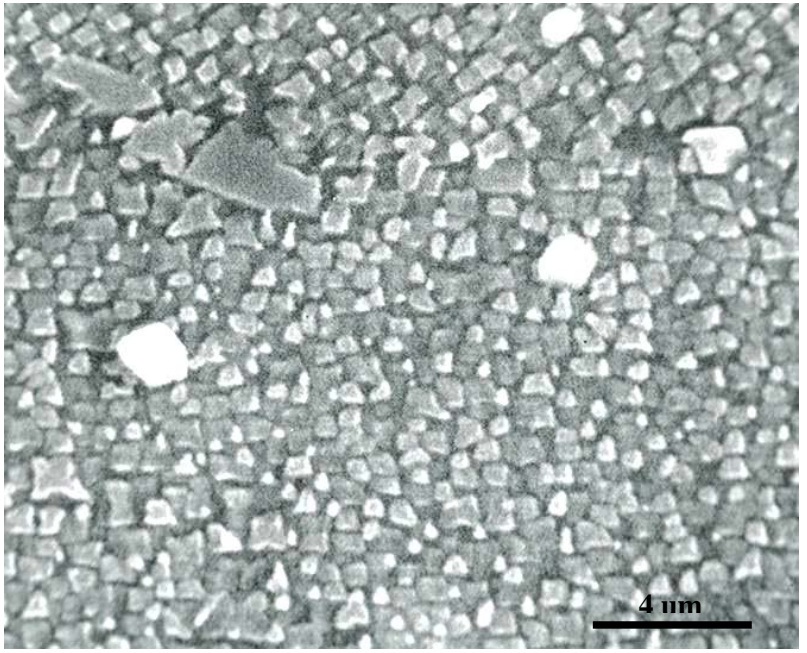

Figure 4. Photomicrograph of the microstructure from Alloy-1 after processing with the western-type heat treatment. (Solution heat treatment cycle $\mathrm{B}+760^{\circ} \mathrm{C} / 16 \mathrm{hr}$ age.)

The alternate heat treatments $\left(2210^{\circ} \mathrm{C} / 2 \mathrm{hrs} / \mathrm{FC}\right.$ to $\left(871^{\circ} \mathrm{C} / \mathrm{AC}\right.$ or $\left.760^{\circ} \mathrm{C} / \mathrm{AC}\right)+871^{\circ} \mathrm{C} / 32 \mathrm{hrs} / \mathrm{AC}$ ) were assessed to determine if these thermal routes would produce microstructures more closely resembling that observed in the Russian EP741NP disc material sample [4]. Metallography, extraction and X-ray diffraction were also performed on the EP741NP alloys given the alternate heat treat treatments. Figures 5 and 6 show the typical microstructures that formed in the EP741NP Alloy-1 and Alloy-2 materials processed with the alternate heat treatment cycles.

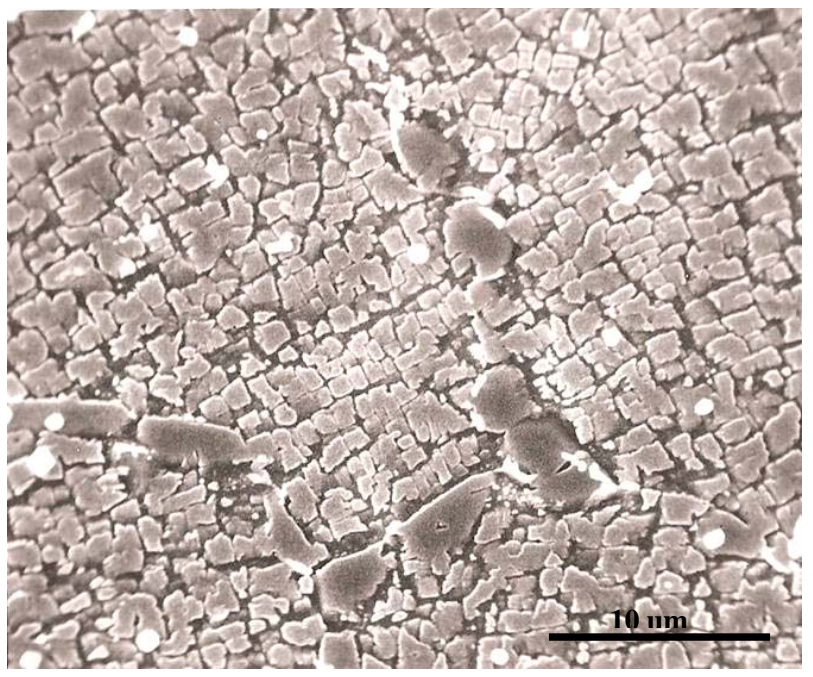

Figure 5. Microstructure of EP741NP Alloy-1 after processing with the alternate heat treatment method $\left(1210^{\circ} \mathrm{C} / 2 \mathrm{hrs} / \mathrm{FC}\right.$ $\left(2.4^{\circ} \mathrm{C} / \mathrm{min}\right.$ ) to $871^{\circ} \mathrm{C} / \mathrm{AC}+871^{\circ} \mathrm{C} / 32 \mathrm{hrs} / \mathrm{AC}$ ). (Solution heat treatment cycle $\mathrm{C}+$ age.) 


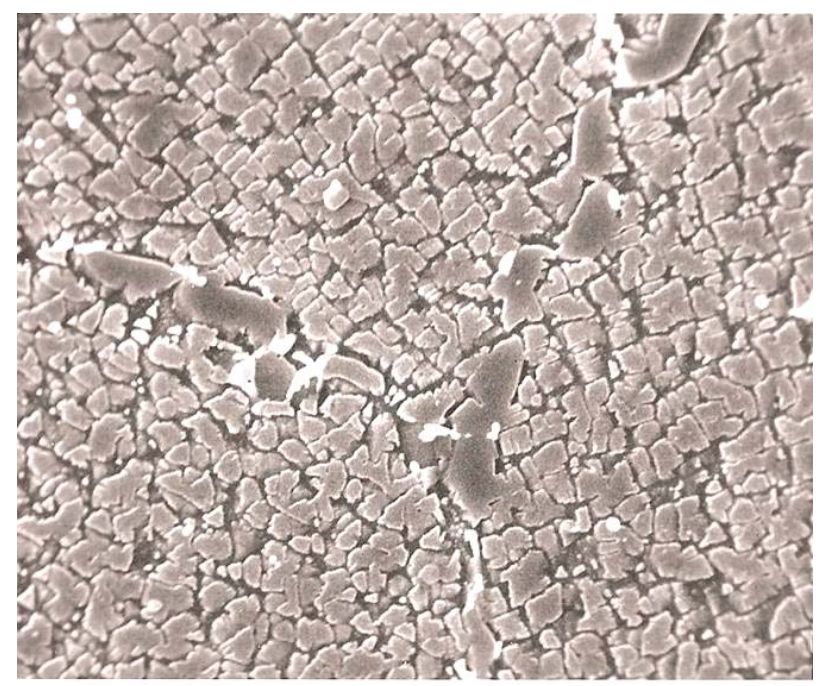

Figure 6. Microstructure of EP741NP Alloy-1 after processing with the alternate heat treatment method $\left(1210^{\circ} \mathrm{C} / 2 \mathrm{hrs} / \mathrm{FC}\right.$ at $2.4^{\circ} \mathrm{C} / \mathrm{min}$ to $760^{\circ} \mathrm{C} / \mathrm{AC}+871^{\circ} \mathrm{C} / 32 \mathrm{hrs} / \mathrm{AC}$ ). (Solution heat treatment cycle $\mathrm{D}+$ age.)

The effect of the cooling rate of the furnace cooling step was investigated. It was believed that the control of the cooling rate would have a significant effect on the final gamma-prime morphology and subsequently the final mechanical property capabilities. Figure 7 shows the results of the furnace cooling at a slightly faster cooling rate, which produced a microstructure that matches well with that from the Russian disc material.

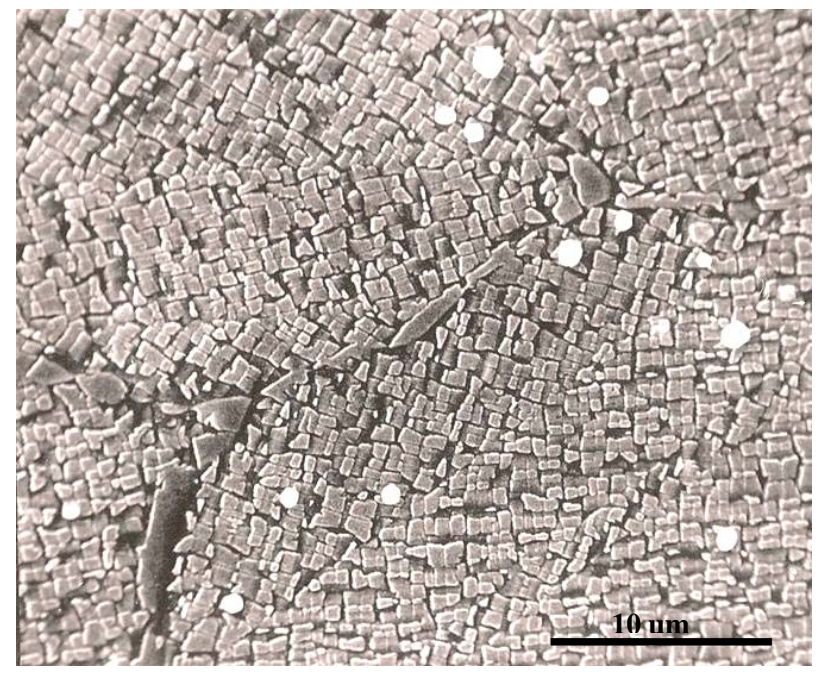

Figure 7. Microstructure of EP741NP Alloy-1 after processing with the alternate heat treatment method $\left(1210^{\circ} \mathrm{C} / 2 \mathrm{hrs} / \mathrm{FC}\right.$ at $3.8^{\circ} \mathrm{C} / \mathrm{min}$ to $760^{\circ} \mathrm{C} / \mathrm{AC}$ ). (Solution heat treatment cycle E.)

A sample from Alloy-1 and Alloy-2 subjected to solution heat treatment $\mathrm{E}$ was re-solution heat treated at a subsolvus temperature to investigate the affect on the gamma-prime morphology. Figure 8 shows the microstructure from the material that was given the subsolvus solution cycle F.

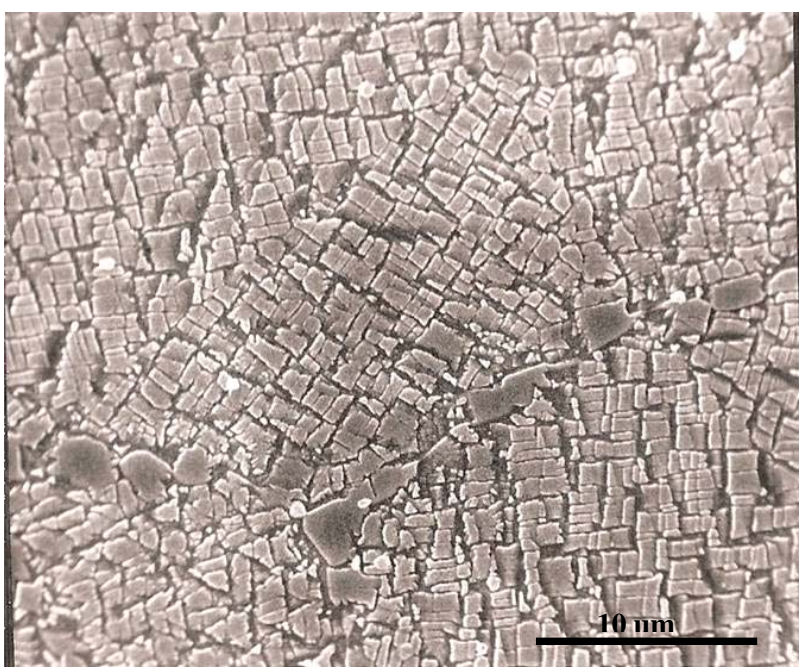

Figure 8. Microstructure of EP741NP Alloy-1 after heat treating with supersolvus solution cycle $\mathrm{E}$ and subsequently with subsolvus solution cycle F.

The microstructures of all mechanical test bar samples were investigated. The microstructure of this alloy appeared to be very stable with very limited change in gamma-prime morphology after the $871^{\circ} \mathrm{C}$ stress-rupture testing. Figure 9 shows the microstructure of the original Russian disc material after $871^{\circ} \mathrm{C}$ creep testing.

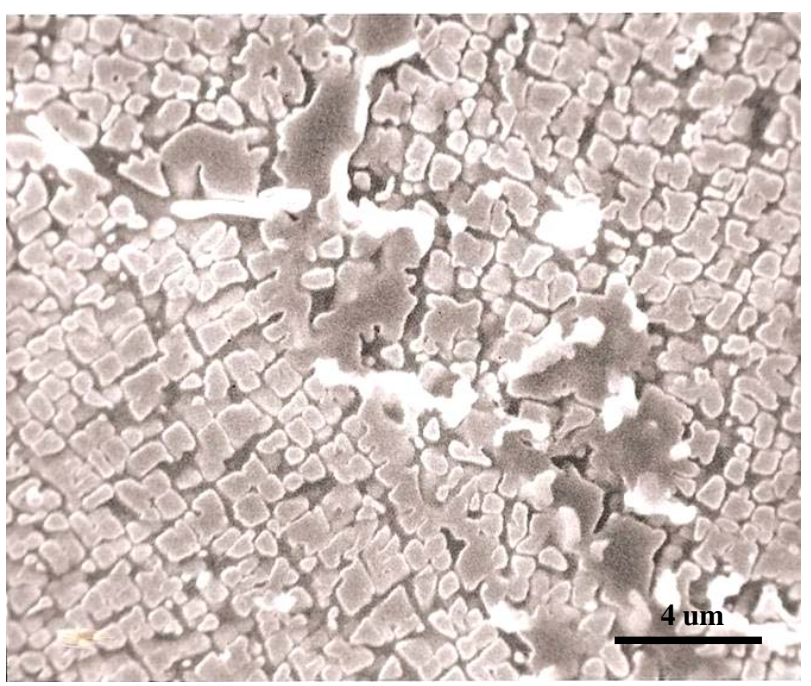

Figure 9. Microstructure of the original Russian disc material after an $871^{\circ} \mathrm{C} / 207 \mathrm{MPa}$ creep test.

The fracture surfaces on the notched stress-rupture samples were very interesting. The materials given the published heat treatment showed ductile fracture surfaces on the notched stress-rupture samples, while the materials heat treated with the western-type 
heat treatment showed brittle, intergranular fracture for a portion of each fracture surface.

Phase Extraction and X-ray Identification. The inert particles with Alloy-1 and Alloy-2 were electrolytically extracted in a $10 \% \mathrm{HCl}$-methenol solution. The phases present in the extracted residues were identified by X-ray diffraction.

Both alloys showed the presence of a Mu phase, $\mathrm{M}_{6} \mathrm{C}$ and $\mathrm{MC}$ phase. $\mathrm{HfO}_{2}$ was found in Alloy-1 due to the presence of $\mathrm{Hf}$ in this alloy.

Mechanical Properties. The tensile properties of the as-received EP741NP disc material and program alloy materials were tested. The strength properties of these materials are shown in Table 2. The tensile properties are shown to be greatly influenced by the heat treatment applied.

Creep and stress-rupture tests were performed on EP741NP Alloy-1 and Alloy-2. These tests were conducted to determine the elevated temperature and stress capability of those materials that were heat treated to the published heat treatment, the western-type heat treatment, and the alternate heat treatment $\left(1210^{\circ} \mathrm{C} / 2 \mathrm{hrs} / \mathrm{FC}\right.$ $2.4^{\circ} \mathrm{C} / \mathrm{min}$ to $871^{\circ} \mathrm{C} / \mathrm{AC}+871^{\circ} \mathrm{C} / 32 \mathrm{hrs} / \mathrm{AC}$ ). Additionally, notched stress-rupture tests were conducted to assess the effects of heat treatment and hafnium content on notch sensitivity and notch ductility. Table 3 listed the creep and stress-rupture from this project effort.

\section{Discussion}

Effect of Chemistry and Heat Treatment on Microstructure Evolution.

The heat treatment studies that were performed were an attempt at duplication of the microstructure observed in Russian process EP741NP [4] and to identify the heat treatment cycle used for the production disc material. It was thought that lowering the temperature to which the samples were furnace cooled after solution treated would strongly influence the resultant microstructure and associated mechanical properties, which was confirmed. It was also thought that the exact cooling rate for the furnace cool would be very critical for the development of the optimal gamma-prime morphology, which was also confirmed.

The formation of the relatively regular, uniform size cuboidal gamma-prime in these alloys is thought to be due to the partitioning of $\mathrm{Nb}$, Ta and refractory alloys between the gammaprime and gamma phases. The partitioning of these elements provides for lattice parameters that result in large misfit strains and sharpening up of the gamma-prime cuboidal shape. The development of an essentially mono-modal distribution of large cuboidal gamma-prime structure is similar to that seen in heat treated cast blade materials that are utilized at very high temperatures.

TABLE 2. Tensile properties of the EP741NP disc material and program alloy forgings.

\begin{tabular}{|c|c|c|c|c|c|}
\hline Alloy & $\begin{array}{l}\text { Heat Treatment } \\
\quad \text { (inluding } \\
871 \mathrm{C} / 32 \mathrm{hr} \text { age) }\end{array}$ & YS (MPa) & UTS (MPa) & $\% \mathrm{E}$ & $\% \mathrm{RA}$ \\
\hline EP741NP & Production & 941.0 & 1313.0 & 17.0 & 22.0 \\
\hline EP741NP & Production & 976.0 & 1303.0 & 18.0 & 24.5 \\
\hline 1 & $A$ & 975.6 & 1506.6 & 25.7 & 25.6 \\
\hline 1 & $A$ & 918.4 & 1489.3 & 27.0 & 24.7 \\
\hline 2 & $A$ & 973.6 & 1502.4 & 26.1 & 25.4 \\
\hline 2 & $\mathrm{~A}$ & 924.6 & 1479.7 & 28.6 & 30.7 \\
\hline 1 & $\mathrm{~B}$ & 1035.6 & 1529.3 & 20.6 & 28.1 \\
\hline 1 & $\mathrm{~B}$ & 1035.6 & 1530.7 & 26.0 & 25.7 \\
\hline 2 & $B$ & 1035.6 & 1537.6 & 25.8 & 27.7 \\
\hline 2 & $\mathrm{~B}$ & 1026.0 & 1531.4 & 26.1 & 27.1 \\
\hline 1 & $A$ & 939.1 & 1319.0 & 23.7 & 25.4 \\
\hline 1 & $A$ & 906.7 & 1292.1 & 26.2 & 28.5 \\
\hline 2 & $\mathrm{~A}$ & 918.4 & 1308.0 & 24.9 & 29.8 \\
\hline 2 & $A$ & 875.7 & 1283.2 & 26.7 & 29.2 \\
\hline 1 & $\mathrm{~B}$ & 1019.1 & 1353.5 & 21.5 & 26.4 \\
\hline 1 & $\mathrm{~B}$ & 1012.9 & 1342.5 & 22.8 & 26.4 \\
\hline 2 & $B$ & 1027.4 & 1370.0 & 21.8 & 25.4 \\
\hline 2 & $\mathrm{~B}$ & 1016.3 & 1356.9 & 22.3 & 22.6 \\
\hline 1 & $\mathrm{C}$ & 750.9 & 1192.1 & 29.0 & 32.1 \\
\hline 2 & $\mathrm{C}$ & 755.0 & 1192.8 & 28.9 & 30.2 \\
\hline
\end{tabular}


The addition of niobium is believed to be based on two factors. First, niobium partitions to the gamma-prime and provides a larger volume fraction of gamma-prime. This is consistent with the fact that the gamma-prime solvus is also higher for EP741NP than for many other P/M superalloys. Niobium also provides for increased anti-phase boundary (APB) energy [9], which results in greater high temperature strength capability.

The role of hafnium on the mechanical properties of superalloys is based on solid-solution strengthening of the gamma phase. It is interesting to note that based on thermodynamic calculations, hafnium appears to partition to the initial gamma-prime phase that forms, but then partitions back to the gamma phase at lower temperatures. [4] This reversal of partitioning is very unusual and may be significant in understanding the total extent of the role of hafnium in superalloys. Hafnium may also affect the preferential precipitation of $\mathrm{Mu}$ and $\mathrm{M}_{6} \mathrm{C}$ adjacent to the large gamma-prime particles associated with higher temperature precipitation on grain boundaries during the solution heat treatment cycle.

Hafnium may play a more important role by improving notchrupture ductility by modifying the grain boundaries in EP741NP. The limited results from this effort indicate a potential for this based on increased notched stress-rupture test lives for both published and western-type heat treatment processed materials, although heat treatment route appears to have the dominant effect in controlling notch-sensitivity.

The MC carbides in EP741NP alloys are very stable. The lattice parameter for this phase is $4.40 \AA$, which indicates that this is not totally a niobium carbide, but contains small amounts of Mo, $\mathrm{W}$, $\mathrm{Ti}$ and $\mathrm{Cr}$. This is confirmed by probing of the extracted MC residue particles.

The regular intermetallic phases that are found in other superalloys in a temperature range of $871^{\circ} \mathrm{C}$ and $1150^{\circ} \mathrm{C}$ are $\mathrm{M}_{6} \mathrm{C}$, and $\mathrm{M}_{23} \mathrm{C}_{6}$. The $\mathrm{M}_{6} \mathrm{C}$ phase is high in $\mathrm{Mo}, \mathrm{W}$ and $\mathrm{Cr}$ and is more commonly found at the higher temperatures. $\mathrm{M}_{23} \mathrm{C}_{6}$ is always found if sufficient carbon is available. In addition to being temperature dependant, $\mathrm{M}_{6} \mathrm{C}$ is generally formed within the matrix while $\mathrm{M}_{23} \mathrm{C}_{6}$ is found as discrete particles in the grain boundaries at $871^{\circ} \mathrm{C}$.

The presence of Mu phase due to aging at $871^{\circ} \mathrm{C}$ shows that $\mathrm{Mu}$ phase is the predominate phase reaction at $871^{\circ} \mathrm{C}$ and not $\mathrm{M}_{23} \mathrm{C}_{6}$ in the EP741NP alloys. Mu and $\mathrm{M}_{6} \mathrm{C}$ seemed to be native of the precipitate in the grain boundaries.

TABLE 3. Creep and stress-rupture properties for EP741NP Alloy-1 and Alloy-2.

\begin{tabular}{|c|c|c|c|c|c|c|c|c|c|}
\hline Temp $\left({ }^{\circ} \mathrm{C}\right)$ & Stress (MPa) & Material & Alloy & \begin{tabular}{|l}
$\begin{array}{l}\text { Heat Treatment } \\
\text { (including } \\
871 \mathrm{C} / 32 \mathrm{hr} \text { age) }\end{array}$ \\
\end{tabular} & \begin{tabular}{|c|} 
Time to \\
$0.1 \%$ Creep \\
(hrs)
\end{tabular} & $\begin{array}{c}\text { Time to } 0.2 \% \\
\text { Creep (hrs) }\end{array}$ & $\begin{array}{c}\text { Time to } \\
\text { Failure } \\
\text { (hrs) }\end{array}$ & $\% \mathrm{EL}$ & Test Type \\
\hline 649 & 690 & Disk Material & EP741NP & Production & - & - & * & $\mathrm{NA}$ & Smooth Creep-Rupture \\
\hline 871 & 207 & Disk Material & EP741NP & Production & - & - & 394.2 & $\mathrm{NA}$ & Smooth Creep-Rupture \\
\hline 704 & 690 & Disk Material & EP741NP & Production & - & - & 1090 & $\mathrm{NA}$ & Smooth Creep-Rupture \\
\hline 704 & 690 & Program Forging & 1 & $\mathrm{~A}$ & 106 & 209.4 & $\mathrm{NA}$ & $\mathrm{NA}$ & Smooth Creep-Rupture \\
\hline 704 & 690 & Program Forging & 1 & $\mathrm{~B}$ & 109.6 & 348 & 1717 & 3.6 & Smooth Creep-Rupture \\
\hline 700 & 500 & Program Forging & 1 & $\mathrm{~A}$ & 752.2 & discontinued & $\mathrm{NA}$ & $\mathrm{NA}$ & Smooth Creep-Rupture \\
\hline 700 & 500 & Program Forging & 1 & $\mathrm{~B}$ & 1254 & $1280^{\star \star}$ & $\mathrm{NA}$ & $\mathrm{NA}$ & Smooth Creep-Rupture \\
\hline 725 & 500 & Program Forging & 1 & $\mathrm{~A}$ & 243.5 & discontinued & $\mathrm{NA}$ & $\mathrm{NA}$ & Smooth Creep-Rupture \\
\hline 725 & 500 & Program Forging & 1 & $B$ & 468.5 & discontinued & NA & NA & Smooth Creep-Rupture \\
\hline 704 & 690 & Program Forging & 2 & $A$ & 89 & 184 & 1960 & 6.1 & Smooth Creep-Rupture \\
\hline 704 & 690 & Program Forging & 2 & $\mathrm{~B}$ & 142.3 & 351 & 1205 & 2 & Smooth Creep-Rupture \\
\hline 700 & 500 & Program Forging & 2 & $\mathrm{~A}$ & 1530 & discontinued & NA & $\mathrm{NA}$ & Smooth Creep-Rupture \\
\hline 700 & 500 & Program Forging & 2 & $\mathrm{~B}$ & 1260 & $1338^{\star \star *}$ & NA & $\mathrm{NA}$ & Smooth Creep-Rupture \\
\hline 725 & 500 & Program Forging & 2 & $\mathrm{~A}$ & 208.8 & 524 & $\mathrm{NA}$ & $\mathrm{NA}$ & Smooth Creep-Rupture \\
\hline 725 & 500 & Program Forging & 2 & $\mathrm{~B}$ & 418 & discontinued & NA & NA & Smooth Creep-Rupture \\
\hline 750 & 690 & Program Forging & 1 & $A$ & 2.4 & 4.9 & 172 & 7.9 & Smooth Creep-Rupture \\
\hline 760 & 500 & Program Forging & 1 & $A$ & 21.4 & 53 & $\mathrm{NA}$ & $\mathrm{NA}$ & Smooth Creep-Rupture \\
\hline 760 & 500 & Program Forging & 1 & $B$ & 50.2 & 117 & NA & NA & Smooth Creep-Rupture \\
\hline 704 & 690 & Program Forging & 1 & $A$ & 104 & 195 & NA & NA & Smooth Creep-Rupture \\
\hline 704 & 690 & Program Forging & 1 & $\mathrm{~B}$ & 163 & 386 & NA & NA & Smooth Creep-Rupture \\
\hline 750 & 690 & Program Forging & 2 & $\mathrm{~A}$ & 2.3 & 4.7 & 136 & 9.9 & Smooth Creep-Rupture \\
\hline 750 & 690 & Program Forging & 2 & $\mathrm{~B}$ & 5 & 14.5 & 135 & 5.5 & Smooth Creep-Rupture \\
\hline 760 & 500 & Program Forging & 2 & $\mathrm{~A}$ & 21.3 & 51 & $\mathrm{NA}$ & $\mathrm{NA}$ & Smooth Creep-Rupture \\
\hline 760 & 500 & Program Forging & 2 & $\mathrm{~B}$ & 12.3 & 73.3 & $\mathrm{NA}$ & $\mathrm{NA}$ & Smooth Creep-Rupture \\
\hline 704 & 690 & Program Forging & 2 & $\mathrm{~A}$ & 65.7 & 154 & $\mathrm{NA}$ & $\mathrm{NA}$ & Smooth Creep-Rupture \\
\hline 704 & 690 & Program Forging & 2 & $\mathrm{~B}$ & 118 & 300 & $\mathrm{NA}$ & NA & Smooth Creep-Rupture \\
\hline 750 & 690 & Program Forging & 1 & $\mathrm{~A}$ & - & - & 216.6 & 7.5 & Smooth Creep-Rupture \\
\hline 750 & 690 & Program Forging & 1 & $\mathrm{~B}$ & - & - & 90 & Notch Break & Combo Smooth/Notched Rupture \\
\hline 750 & 690 & Program Forging & 2 & $\mathrm{~A}$ & - & - & 193.1 & 8.5 & Combo Smooth/Notched Rupture \\
\hline 750 & 690 & Program Forging & 2 & $\mathrm{~B}$ & - & - & 0.1 & Notch Break & Combo Smooth/Notched Rupture \\
\hline 750 & 690 & Program Forging & 1 & $\mathrm{C}$ & - & - & 111 & 9.5 & Combo Smooth/Notched Rupture \\
\hline 750 & 690 & Program Forging & 2 & $\mathrm{C}$ & - & - & 106.7 & 10.5 & Combo Smooth/Notched Rupture \\
\hline
\end{tabular}

* Sample exhibited $0.0 \%$ creep after $1500 \mathrm{hrs}$, so sample was re-tested at 704C/690MPa

** Temperature increaed to $750 \mathrm{C}$ and stress increased to $552 \mathrm{MPa}$ at 1254 hrs

*** Temperature increased to $750 \mathrm{C}$ at $1260 \mathrm{hrs}$ 
Long exposures at $750^{\circ} \mathrm{C}$ can produce the onset of $\mathrm{M}_{23} \mathrm{C}_{6}$ precipitation on grain boundaries. The formation of $\mathrm{M}_{23} \mathrm{C}_{6}$ appears to be reduced by the addition of niobium and hafnium, and the utilization of the high temperature aging treatment which stabilized the structure through the formation of $\mathrm{Mu}$ phase. This feature of EP741NP may provide for excellent high temperature stability where grain boundary $\mathrm{M}_{23} \mathrm{C}_{6}$ films may not form and embrittle the material as has been seen with other alloys.

The evolution of phases in EP741NP with and without hafnium appears to progress as follows: Large amounts of primary MC carbide is formed and stabilized at the solution heat treatment temperature. As the materials are slow cooled, a regular array of intragranular cuboidal gamma-prime is formed along with $\mathrm{M}_{6} \mathrm{C}$, until the material reaches $871^{\circ} \mathrm{C}$, where $\mathrm{Mu}$ phase also begins to precipitate.

The microstructure developed in the EP741NP materials utilizing the published heat treatment route did not provide the same microstructure as that observed in production disc material. This is thought to be due to the fact that the cooling route in the published method must be different than that used for the production disc component.

The processing of P/M EP741NP material is very unique. A very high temperature HIP cycle is used [1], which is believed to be aimed at dissolution of prior particle boundaries and stabilization of primary MC carbides. The chemistry and microstructure designed for the production EP741NP material appears to be targeted at very high temperature applications. The strength of this alloy in the production heat treatment conditions is not very high, although the elevated temperature creep strength is superior to other comparable disc alloys and processes. The microstructure, which consists of a very coarse, as-HIP'd gamma grain size, and a single distribution of cuboidal gamma-prime (similar to blade alloy microstructures). The high temperature strength, though modest, may be higher than other comparable materials, due to the increase in gamma-prime phase strengthening and stability from the addition of niobium, and hafnium solid-solution strengthening of the gamma-phase. The very long (32hrs), high temperature $\left(871^{\circ} \mathrm{C}\right)$ age cycle, may actually be a stabilization cycle where near equilibrium compositions of $\mathrm{M}_{6} \mathrm{C}, \mathrm{Mu}$, gamma and gamma-prime phases are formed and stabilized. The extensive partitioning of chromium to the gamma phase may also enable high temperature application with enhanced corrosion resistance. EP741NP has been observed to be much more difficult to electrolytically etch than other nickel-base alloys, and required much longer etching time. The heat treatment method also provides for a large gamma-prime content and an ability to process large section-size components with limited risk of thermally-induced (quench) cracking as furnace cooling is employed following the solution heat treatment.

Effect of Heat Treatment and Chemistry on Tensile, Creep and Stress-Rupture Properties of EP741NP.

A study to determine the effects of thermal processing and alloy chemistry on the mechanical property behavior of EP741NP material was performed. The two program heats of EP741NP material, one containing $\mathrm{Hf}$ and the other without, were given the published heat treatment for EP741NP (solution cycle A), a western heat treatment (solution cycle B) and an alternate heat treatment involving furnace cooling from $1210^{\circ} \mathrm{C}$ to $871^{\circ} \mathrm{C}$ at a relatively low rate (solution cycle $\mathrm{C}$ ). All of the materials were aged at $871^{\circ} \mathrm{C}$ for 32 hours. The samples were tensile, creep and stress-rupture tested over a range of temperatures and stresses.

The tensile properties of EP741NP are sensitive to heat treatment and final developed microstructure. Figure 10 shows the comparison of yield strength properties for the program materials along with that of the production disc material. It can be seen that the material with the finest gamma-prime structure resulted in the highest tensile properties. The program materials heat treated with solution heat treatment "A" provided slightly lower properties as compared to the production disc material.

The strength of this alloy appears to be controlled by both the size and distribution of the initial, larger gamma-prime size population and the size and distribution of a secondary, smaller size gammaprime particle population. This is similar to blade alloys which have a large volume fraction of cuboidal gamma-prime and very small gamma-prime with the gamma matrix between the larger gamma-prime particles.

The material given solution heat treatment " $C$ " appeared to have a similar microstructure to that of the disc material, but the large gamma-prime particles were larger and less cuboidal. The slow cooling of this cycle to the aging temperature appears to have greatly reduced or eliminated secondary gamma-prime particles and hence greatly reduced the tensile strength.

Creep and stress rupture testing was performed on the program materials. In addition to smooth test bars, notched stress-rupture bars were utilized to assess notch sensitivity of the materials processed by the various heat treatments.

Figure 11 shows a Larsen-Miller stress-rupture plot for the stressrupture results from the program materials along with published EP741NP values and prior published U720 properties [4]. It can be seen that the stress-rupture capabilities of EP741NP are very good compared to U720 disc and blade materials.

Notch sensitivity assessments were also performed. The results showed that the hafnium containing sample given solution cycle B broke in the notch of notched stress-rupture specimen after 90 hours, while the one without hafnium broke in 0.1 hours. The samples given solution heat treatment cycle A did not suffer notch failures, and failed in 216 hours (hafnium-containing alloy) and 193 hours (Hf-free alloy). The samples given solution heat treatment cycle $\mathrm{C}$ did not show notch failures, and had stressrupture lives of approximately 110 hours.

The structures of the samples given the published heat treatment did not produce the microstructure observed in the original Russian disc material, and showed large irregular gamma-prime and fine secondary gamma-prime. The samples given the western-type heat treatment showed only very fine, uniform gamma prime. The alternate heat treatment samples showed microstructures much closer to those of the Russian disc material, but the size scale and morphology of the gamma-prime was slightly different. 


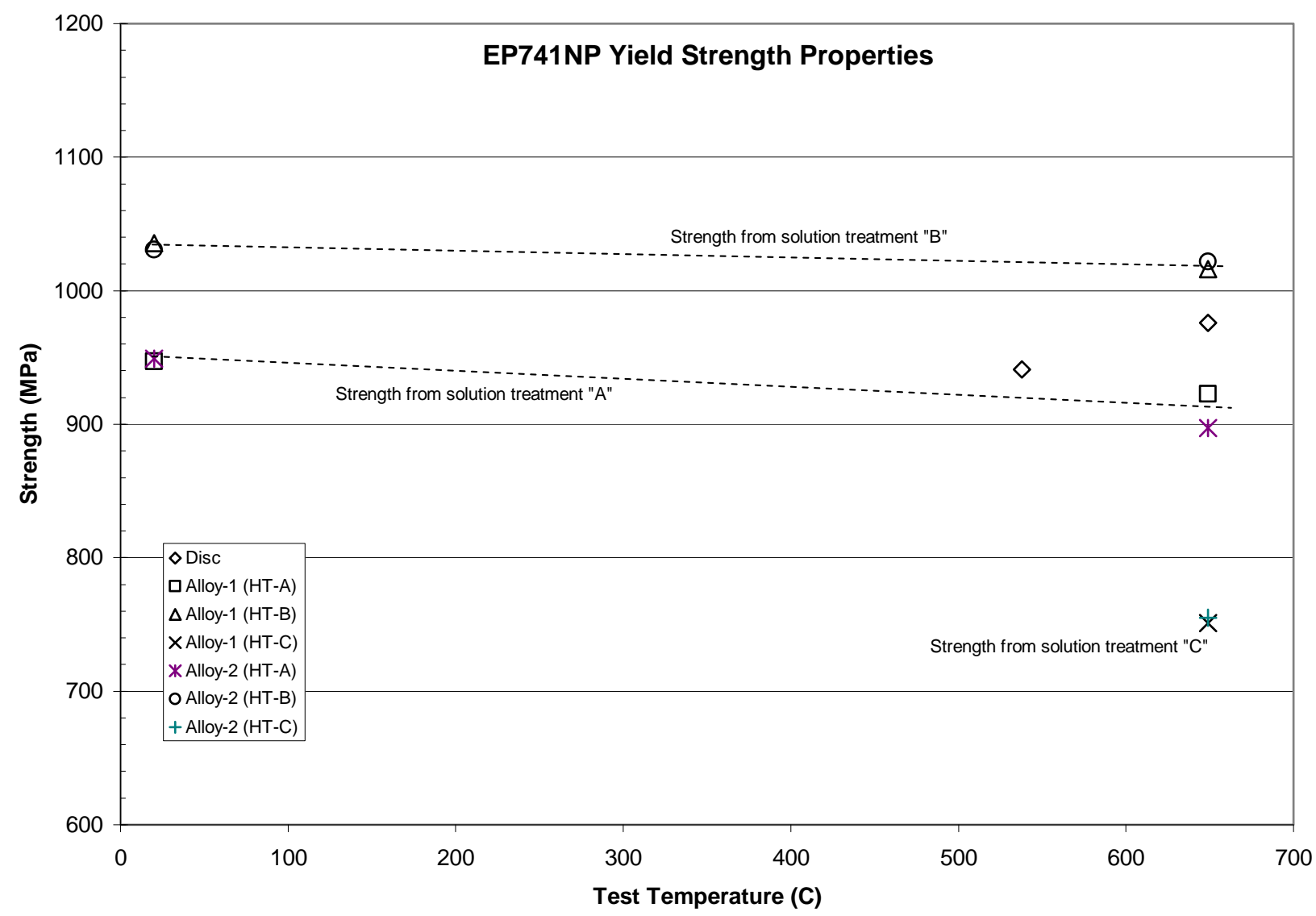

Figure 10. Plot of yield strength properties for EP741NP disc material and program materials after a series of different heat treatments.

The sample given solution heat treatment $\mathrm{B}$ that broke in 0.1 hours showed fewer grain boundary precipitates than the sample that broke at 90 hours. Selective etching showed that the grain boundaries contained limited amounts of $\mathrm{M}_{23} \mathrm{C}_{6}$ as evidence from observations after selectively etching for chromium-rich phases. The formation of $\mathrm{M}_{23} \mathrm{C}_{6}$ was seen only after long thermal exposures.

Notch sensitivity of the EP741NP material was shown to be strongly related to the microstructure and tensile strength. As the material increased in tensile strength and increased in quantity of fine gamma-prime, notch sensitivity increased and stress-rupture lives decreased. Additionally, it appears that the presence of hafnium may play a secondary, beneficial role in increasing stress-rupture life when comparing similar microstructure/strength materials. Hafnium is potent in binding oxygen and may influence the grain boundary oxygen content in EP741NP.

The stress-rupture fracture modes for the materials processed with solution heat treatment B showed portions of the fracture surface that are intergranular. This indicates weaker grain boundaries as compared to the matrix material, which is consistent with the observation of grain boundaries with limited precipitation of phases as evidenced from the metallography, extraction and XRD efforts on the EP741NP Alloy-1 and Alloy-2 samples given the western-type heat treatment.

The creep and smooth stress-rupture strength of EP741NP appears to be favorable over U720 disc material at high temperature, low stress conditions and U720 blade material as low temperature, high stress conditions. Under low temperature, high stress conditions, material that is higher in tensile strength prevails. This was seen with the combinations of heat treatments that were performed on the EP741NP materials.

The fracture surface of tested stress-rupture bars from the original EP741NP disc material that was consolidated by HIP processing primarily showed clear prior particle boundary (PPB) failures. The fracture surfaces from these tested specimens showed an array of spherical particle surfaces at the fracture surface.

The program material samples that were consolidated by extrusion showed no evidence of PPBs or original particle surfaces on the fracture surface of any stress-rupture specimen. This is consistent with the use of extrusion consolidation methods. 


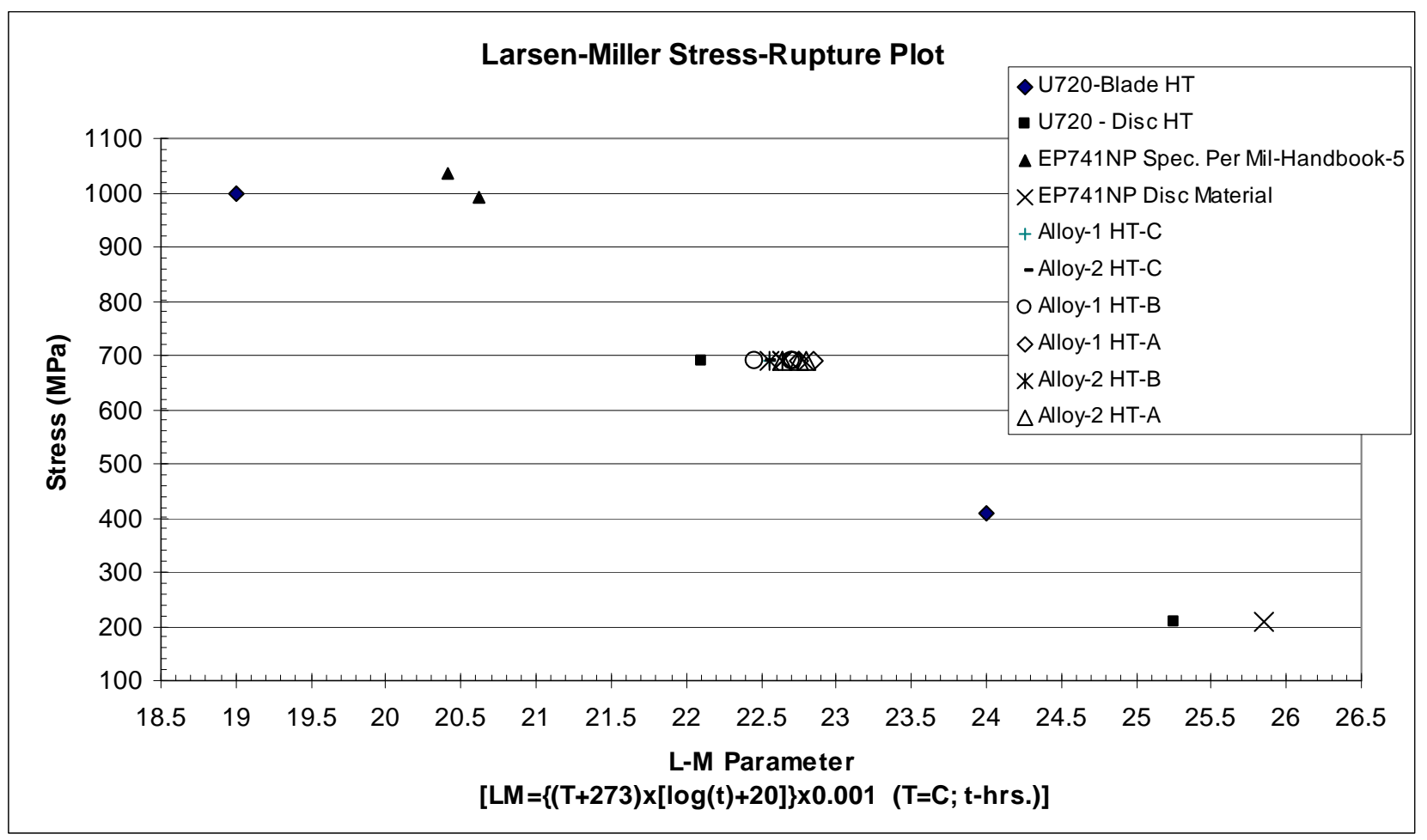

Figure 11. Larsen-Miller stress-rupture plot for EP741NP and published U720 material properties.

\section{Conclusions}

An alloy assessment program was undertaken to investigate the effects of chemistry and processing on the microstructure and mechanical properties development in powder metallurgy EP741NP. Extensive metallographic and crystallographic investigations were undertaken to study the microstructure and phases within the program materials. Stress-rupture testing was performed to assess the effects of chemistry and microstructure. The results of these efforts indicated:

- The critical steps in the heat treatment used to manufacture production EP741NP discs have been identified.

- The cooling rate following supersolvus solution heat treatment was shown to greatly influence the phase selection and microstructure within advanced powder metallurgy superalloys.

- Stress-rupture ductility debits and notch sensitivity can result from high volume fractions of fine gamma-prime.

- The results from this effort showed that hafnium additions had a beneficial effect on improving notch sensitivity in high strength material.

- Niobium appears to enhance the capability of formation of stable $\mathrm{MC}, \mathrm{M}_{6} \mathrm{C}$ and $\mathrm{Mu}$ phases along with a uniform single distribution of cuboidal gamma-prime.
- Mu-phase formation in the place of $\mathrm{M}_{23} \mathrm{C}_{6}$ carbides during the long, high temperature aging cycle appears to provide enhanced high temperature capability with limited effect of grain boundary film formation during long, high temperature exposures.

- The alloy displayed very good phase and microstructure morphology stability with limited phase precipitation on grain boundaries and gamma-prime morphology change after extended high temperature exposure.

- The unique creep capabilities of this alloy due to the high concentration of relatively coarse cuboidal gamma-prime and lack of $\mathrm{M}_{23} \mathrm{C}_{6}$ grain boundary films may fit high temperature applications.

\section{Acknowledgements}

The authors would like to thank Reference Metals Inc. for support for alloy manufacture, forging and microstructural characterization and Ladish Forging for support for mechanical property testing. The authors would like to acknowledge and thank Fan Zhang and CompuTherm for thermodynamic modeling support within this effort. 


\section{References}

1. T.P. Gabb, J.Gayda, P.T. Kantzos, T.Biles, and W.A.Konkel, "The Tensile Properties of Disk Superalloys During Supersolvus Quenching Heat Treatments,” Materials Design Approaches and Experiences, eds., J.-C. Zhao, M.Fahrmann, and T.M. Pollock, TMS, 2001, pp. 267-279.

2. J. Gayda, "High Temperature Fatigue Crack Growth Behavior of Alloy 10,” NASA TM 2001-210814, April 2001.

3. J. Gayda, T. Gabb, P. Kantzos and D. Furrer, "Heat Treatment Technology for Production of Dual Microstructure Superalloy Disks,” NASA TM 2002-211558.

4. J.Radavich and D.Furrer, "Assessment of Russian P/M Superalloy EP741NP,” Superalloys 2004, eds., K.A. Green, et. al., TMS, 2004, pp. 381-380.

5. T. Carneiro, J. Radavich and D. Furrer, "The Role of Niobium in Nickel-Base Superalloys and Characterization of PM Alloy EP741NP," Proceedings of the Sypmosium on Superalloy Technology, Dalian, China, July, 2004

6. J.Radavich, T.Carneiro, D.Furrer, J.Lemsky and A.Banik, "The Effect of Processing and Composition on the Structure and Properties of P/M EP741NP Type Alloys," Chinese J. of Aeronautics, 20 (2007) pp. 97-106.

7. J. Radavich, T.Carneiro, D.Furrer, J.Lemsky and A.Banik, "The Effect of Hafnium, Niobium, and Heat Treatment on Advanced Powder Metallurgy Superalloys”, Proceedings of the Eleventh International Symposium on Advanced Superalloys, Chinese Society for Metals, May 21-25, 2007, Shanghai, China, pp. 114-124.

8. D.R. Muzyka, "Physical Metallurgy and Effects on Processing Variables on the Microstructure of Wrought Superalloys," MiCon78, ASTM, 1979, pp. 526-546.

9. G.D. Smith, S.J. Patel, "The Role of Niobium in Wrought Precipitation-Hardened Nickel-Base Alloys," Superalloys 718, 625, 706 and Derivatives, TMS, 2005, pp. 135-154. 